\title{
The Effects of a Bonus Tax on Manager Compensation and Welfare
}

\author{
Doina Radulescu
}

CESIFO WORKING PAPER No. 3030

CATEgOry 1: Public FinANCE

APRIL 2010

\footnotetext{
An electronic version of the paper may be downloaded

- from the SSRN website: www.SSRN.com

- from the RePEc website:

- from the CESifo website: 


\title{
The Effects of a Bonus Tax on Manager Compensation and Welfare
}

\begin{abstract}
This paper analyses the implications of a currently publicly debated issue, namely the introduction of a bonus tax. We shed light on the effects of the bonus tax on compensation components and study its incidence. We use the Principal Agent model within a two-country framework and consider two main scenarios. In the first scenario the firm cannot relocate managers between countries whereas in the second scenario relocation possibilities exist. Our findings show that the effort based compensation component always rises in the country introducing the tax such that the optimal contracts are tilted towards more effort based pay. Moreover, the bonus tax negatively affects profits and dividends and thus the incidence falls on the firm's shareholders. With no relocation possibilities, the country that does not introduce such a tax will be worse off in terms of welfare, as the dividend income accruing to its residents declines. Accordingly, the bonus tax can be interpreted as a transfer from the worldwide shareholders to the government levying the tax. However, the welfare results may be reversed when manager relocation is an alternative. In this case, welfare in the country introducing the tax is lower than in the no relocation scenario, while the country that does not levy a bonus tax might even gain in welfare terms.
\end{abstract}

JEL-Code: H24, H22, J22, J30.

Keywords: bonus tax, labor taxation, effort, manager compensation, welfare.

\author{
Doina Radulescu \\ ETH Zurich \\ Weinbergstrasse 35 \\ Switzerland - 8092 Zurich \\ radulescu@kof.ethz.ch
}

I would like to thank Peter Egger, Doug Nelson and Ray Rees for fruitful discussions about the topic and discussants at various conferences for insightful comments. 


\section{Introduction}

One of the main topics that has dominated policy discussions all over Europe during the past four months has been the introduction of a bonus tax by the UK and France. The British Treasury announced at the beginning of December that it would impose a one-off ex-post 50\% levy on any discretionary bonuses exceeding GBP 25,000 (Euro 28,000) ${ }^{1}$ awarded to employees of banks for the period 9 December 2009 to 5 April 2010. Alistair Darling, the British chancellor, defended this measure by arguing that banks should use their profits to strengthen their capital base instead of paying high bonuses. On these grounds, the proceeds from this bonus tax, would be spent, according to Darling, to refund taxpayers' money which was used for rescuing banks (Financial Times, 9 December 2009). The French Finance Minister Christine Lagarde also announced that France would levy a tax on bonuses exceeding Euro 27,500 in 2010. Even the Social Democratic Party of Switzerland proposes a bonus tax of $8.5 \%$ for bonuses exceeding CHF $1 \mathrm{mn}$, as a response to excessively high payments.

Moreover, it will be interesting to see the European Commission's stance on these issues given that it is expected to release a paper on measures it aims to support at the G20 meeting in June in Canada. One of the main themes of the summit is financial sector reform where the leaders will discuss measures 'to help reduce excessive risk taking and to encourage a culture of prudent behaviour focused on the long term'.(Toronto Summit, 2010) Therefore, given the increasing support for such a controversial measure, it is important to analyse its possible implications.

Figure 1 depicts the evolution of the City of London bonus payouts between 2001 and 2012. One can note the clear peak in 2006 and 2007 when bonuses amounted to around GBP 10 bn and were thus 41 per cent higher than in 2005. Finally, there was a dramatic drop by around 60 per cent in 2008 to around GBP 4 bn which was almost the 2001 level. Given these numbers and assuming for instance that 50 per cent of the GBP 6 bn distributed in 2009 were discretionary, applying a 50 per cent bonus tax, tax revenues collected by the British government would amount to

\footnotetext{
${ }^{1}$ Except for bonuses guaranteed by contracts.
} 


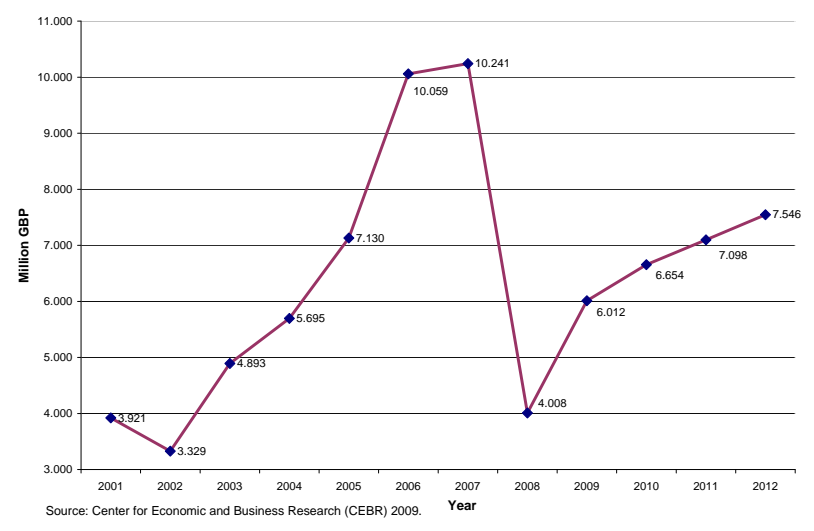

Figure 1: City of London bonus payout

around GBP 1.5 bn.

Therefore, taking into consideration the prominence of as well as the worldwide concern linked to this topic, it is interesting to see what are the implications of introducing such a tax. Since top executives have very high incomes, the way they respond to changes in taxes may have important efficiency as well as revenue implications.

To the best of our knowledge, this is the first paper to address the above mentioned issues. To this purpose we develop a Principal Agent model which captures these effects. We thus consider a firm which operates in two different countries and employs a manager in each of them to run the firm's operations in the respective country. The firm (the principal) writes contracts with each of the two agents. We compute the optimal compensation components in each of the two countries and then consider the effects of the introduction of a tax on the bonus component in one of the two economies. If, in addition, we impose the constraint that net of tax wages have to be equalized between countries and assume equal reservation wages, the net of bonus tax effort based compensation component in the country raising the tax 
has to equal the effort based compensation component in the other country. ${ }^{2}$ Our results are thus consistent with empirical studies that suggest that the elasticity of earnings with regard to taxes is quite high (see Gruber and Saez, 2002 and Giertz, Saez and Slemrod 2009) as opposed to studies which measure a low elasticity of hours worked with respect to taxes. ${ }^{3}$

Moreover, in the first scenario, where managers cannot be relocated between countries, the effort independent wages are also equalized between countries. In general, if we relax the assumption of identical reservation wages but keep the constraint of equal total net compensation, the bonus component will be higher in the country levying the tax if the reservation wage is higher in this economy.

Overall, in all scenarios, given the higher output dependent compensation component, the optimal contracts are tilted towards more effort based pay. On the one hand, the post tax wage the manager receives is lower, however, on the other hand, the introduction of the tax reduces the variance of income since the government now shares part of the risk, and, given the agent's risk aversion, the optimal compensation contract can now include a higher share of effort based pay.

Moreover, the introduction of such a tax reduces a firm's profits and thus dividends. The tax negatively affects effort, such that the firm needs to increase the manager's compensation to induce her to provide more effort. Therefore firm profits are negatively affected such that the incidence of the tax basically falls on the firm's shareholders. This result is in line with the announcement of Deutsche Bank or Credit Suisse who stated the intention to lower dividend payouts as a response to the introduction of the UK bonus tax(Frankfurter Allgemeine Zeitung, 19. December 2009).

Regarding the welfare implications of such a policy, the country which abstains

\footnotetext{
${ }^{2}$ As opposed to the announcement of Josef Ackermann, in this kind of framework it is not possible to lower bonus payments in the no tax economy since the manager's participation constraint would be violated. Such a policy is only viable if the tax is a one time ex post levy. In our framework, the assumption of equal reservation wages and equal net compensation implies that the gross effort based wage component in the country levying the tax has to rise.

${ }^{3}$ The difference in these two kinds of elasticities results from things like unmeasured effort, switching to less heavily taxed forms of remuneration or accepting promotion for instance.
} 
from introducing such a tax might be at a disadvantage, if as assumed in the first scenario, the bank needs to employ a manager at each location, so if we disregard the possible threat of moving any operations to no-tax countries. In this case, the dividend income accruing to its residents declines. The welfare implications for the country imposing the tax depend on the reaction of tax revenue to an increase in the bonus tax as well as on the relationship between the positive tax revenue effect and the negative dividend income effect. Assuming that the so-called home bias holds, the country where the majority of the firm's shareholders reside will be at a disadvantage. ${ }^{4}$

In a second version of the model, we assume the firm employs a number of identical managers at each location and, in addition, has the possibility to relocate managers between countries as a response to a change in the bonus tax. This assumption is in line with the reaction of the majority of financial institutions such as Goldman Sachs, Société Générale, BNP Parisbas, HCBC or JP Morgen which threatened to transfer operations out of the UK. If we extend our welfare function to include labour income tax revenue, the welfare implications change as compared to the case with no relocation. On the one hand, the country introducing the tax will lose now more since the possibility to relocate managers negatively affects both labour income tax revenue and the revenue from the bonus tax. On the other hand, the country that abstains from introducing a bonus tax might even gain in welfare terms if the positive labour income tax revenue effect generated by the relocation of managers exceeds the negative dividend income effect.

Of course, assuming the exogeneous outside option of the manager is not a job in the financial sector of another country, but another sector of the economy where no bonus tax applies, the introduction of the bonus tax for bank employees may alter the allocation of human capital across sectors. This basically confirms concerns which were already raised by banks with regard to the possibility of attracting and keeping talented people in the banking sector in the future. As shown by Philippon

\footnotetext{
${ }^{4}$ Assuming for instance Deutsche Bank shares are mostly held by German compared to UK citizens, German shareholders would lose more compared to UK shareholders as a result of lower Deutsche Bank profit distributions.
} 
and Reshef (2008), wages in the financial sector in the US were excessively high between 1990 and 2006 and $30 \%$ to $50 \%$ of the wage differential to the rest of the private sector is accounted for by rents. Therefore, a tax which just affects the financial sector might improve the allocation of high-skilled human capital across sectors. This is line with the findings of research on the allocation of talent. Accordingly, as Baumol (1990) showed, the relative payoffs to different entrepreneurial activities largely determines the allocation of human capital to unproductive activities such as rent seeking or productive activities such as innovation. Thus, a side effect of the bonus tax, if one believes that the returns in the financial sector are basically high rents, would be an improved allocation of high skilled people who would thus be attracted to work in sectors which benefit the society as a whole more than the financial sector. However, this is not a stated goal of policy makers who discuss the introduction of the bonus tax, so we disregard this aspect in the paper, though it is an important consequence of the tax which can be analysed in future research.

Our findings are in line with well-known results in the field of international taxation, which is not surprising, since we consider managers to be highly mobile and if we interpret the supply of managers the elastic side of the market. Nevertheless, our contribution is to show that similar conclusions can apply to high-skilled, high income earners, and that policy makers should be aware of certain consequences of the discussed policy proposal.

The remainder of the paper is structured as follows. The next Section gives a brief overview of the literature while Section three introduces the model. In Section four we perform a welfare analysis and Section five concludes.

\section{Literature Review}

In spite of the topicality of the issue there is no previous work devoted directly or indirectly to the effects of bonus taxes on the design of the compensation contracts, on tax revenues and thus welfare in different countries. Our work can be attributed to basically two lines of research. The first, including the work of Gupta and Viauroux (2009), Brunello, Comi and Sonedda (2006) and Egger and Radulescu 
(2010) considers the effect of taxes in a Principal Agent model, whereas the second, including mainly two empirical studies by Hall and Liebman (2000) and Katuscák (2009), deals with the effect of personal income taxation on executive compensation.

Using the framework of the Principal Agent model, Gupta and Viaroux (2009) analyse the effects on effort, wages, profits and welfare of different tax sharing rules. Their findings suggest that whereas a $100 \%$ tax on the employer maximizes effort and thus expected profits and welfare, a 100\% tax on the employee maximizes expected wages. Moreover, a sharing rule (as usually applied in OECD countries), where both the employer and the employee pay contributions, does not maximize any of the considered variables. The second study mentioned, by Brunello, Comi and Sonedda (2006), considers how taxes alter the balance between provision of incentives and individual insurance demand, in the optimal composition of pay. The authors show that higher average taxes reduce the share of the performance related compensation component in total pay, whereas the effects of higher marginal taxes are more ambiguous. Finally, Egger and Radulescu (2010) analyse the implications of labour taxes for the location of headquarters of multinational firms and show that income taxes have a negative effect on firms' profits by reducing the agents' effort.

In the second line of research, Hall and Liebman (2009) examine the extent to which tax policy has influenced the composition of executive compensation. Their empirical analysis suggests that tax policy cannot be used as an explanation for the surge in stock-option pay since 1980. However, the authors show that the joint tax efficiency of the executive and his employer leads to nonqualified stock options dominating cash pay if the capital gains tax rate is positive and the stock is expected to appreciate. By using options, executives can avoid capital gains taxation. Nevertheless, increasing the use of options increases risk bearing. However, as pointed out by Katuscák (2009), if the income tax is raised, the tax benefit of options is reduced such that there should be a shift towards using options less. But due to the tax increase, the government shares a higher fraction of the payout such that the risk of option grants is reduced which rebalances the composition of pay towards more options. Using Execucomp data for the time period 1992-1996 and changes in the top marginal income tax rate, Katuscák (2009) shows that a higher tax reduces the 
pre-tax pay-to- performance sensitivity of option grants whereas after-tax incentive provisions are highly responsive to changes in the marginal income tax rate.

Overall, there is no paper trying to answer the question on the effects of introducing a bonus tax in one country. We aim to fill this gap and shed light on this question by extending the Principal Agent model in a two country framework in the next Section.

\section{The Model}

\subsection{No Relocation Possibility}

To look into the effects of the bonus tax on the design of the compensation contracts and welfare, we extend the Principal Agent model as developed by Holmstrom and Milgrom (1987). In this first version of the model, we make the assumption that it is not possible for the financial institution to move any operations and accordingly the employed managers to the no-tax country, following the announcement of the introduction of the tax as it needs to run a local subsidiary in each of the two countries.

We consider a firm which operates in country $i=A, B$ and employs a manager to run the operations in each of the two countries. Accordingly, the net of tax wage of the manager in country $i, w^{i}$ equals

$$
w^{i}=\left(1-t^{L, i}\right)\left(\alpha^{i}+\left(1-t^{B, i}\right) \beta^{i} Q^{i}\right)
$$

where $\alpha^{i}$ and $\beta^{i}$ represent the effort-independent compensation component and output dependent compensation component, respectively, whereas $t^{L, i}$ and $t^{B, i}$ denote the labour and the bonus tax rate in the two countries and $Q^{i}$ output in the respective economy. Since we analyse the unilateral introduction of a bonus tax, we assume from now on that only country A levies such a tax such that $t^{B, B}=0$. Each manager's utility function displays constant risk aversion and is represented by

$$
U^{i}\left(w^{i}, e^{i}\right)=-e^{-r\left(w^{i}-C\left(e^{i}\right)\right)},
$$


where $r=-\frac{u^{\prime \prime}}{u^{\prime}}$ is the coefficient of absolute risk aversion. The principal, is riskneutral in this framework. Working involves some disutility which is captured by the distaste function $C\left(e^{i}\right)$ which, for simplicity, we assume to be $C\left(e^{i}\right)=\frac{1}{2} c\left(e^{i}\right)^{2}$. Since we assume that personal effort is costly, $c$ is a positive constant.

Output is a function of effort $e^{i}$ and luck $v^{\sim} N(0, \sigma)$. Accordingly,

$$
Q^{i}=e^{i}+v
$$

The firm's objective is to maximize its expected profits $\pi$ subject to each of the agent's participation constraint (5) and the incentive compatibility constraint (6). Profits are determined as the sum of expected output $\Sigma_{i} E\left(Q^{i}\right)$ of the two countries the firm operates in, less the compensation paid to each of the two managers:

$$
\underset{\alpha^{i}, \beta^{i}}{\operatorname{Max}} \pi=\Sigma_{i} E\left(Q^{i}\right)-\Sigma_{i}\left(\alpha^{i}+\beta^{i} e^{i}\right),
$$

Profits are maximized subject to

$$
E\left(-e^{-r\left(w^{i}-C\left(e^{i}\right)\right)}\right) \geqslant U\left(\bar{w}^{i}\right)
$$

and

$$
e \underset{\alpha^{i}, \beta^{i}}{\arg \max } E\left(-e^{-r\left(w^{i}-C\left(e^{i}\right)\right)}\right),
$$

where $U\left(\bar{w}^{i}\right)$ represents the agent's reservation utility.

With the chosen functional form, a closed-form solution of the agent's certainty equivalent $(C E)$ to expected utility can be obtained. ${ }^{5} C E$ can be expressed as the manager's expected compensation $\left(\alpha^{i}+\beta^{i} e^{i}\left(1-t^{B, i}\right)\right)\left(1-t^{L, i}\right)$ net of her effort cost $\frac{c\left(e^{i}\right)^{2}}{2}$ and a risk premium $r\left(\beta^{i}\right)^{2}\left(1-t^{L, i}\right)^{2}\left(1-t^{B, i}\right)^{2} \frac{\sigma^{2}}{2}$. The introduction of the bonus tax reduces thus the risk premium that has to be awarded to the managers for the standard reason that the variance of net income decreases.

$$
C E^{i}=\left(\alpha^{i}+\beta^{i} e^{i}\left(1-t^{B, i}\right)\right)\left(1-t^{L, i}\right)-\frac{c\left(e^{i}\right)^{2}}{2}-r\left(\beta^{i}\right)^{2}\left(1-t^{L, i}\right)^{2}\left(1-t^{B, i}\right)^{2} \frac{\sigma^{2}}{2} .
$$

\footnotetext{
${ }^{5}$ See Bolton and Dewatripont (2005) for the derivation.
} 
Using (6), the manager's optimization problem can be translated into

$e \underset{\alpha^{i}, \beta^{i}}{\arg \max }\left[\left(\alpha^{i}+\beta^{i} e^{i}\left(1-t^{B, i}\right)\right)\left(1-t^{L, i}\right)-\frac{c\left(e^{i}\right)^{2}}{2}-r\left(\beta^{i}\right)^{2}\left(1-t^{L, i}\right)^{2}\left(1-t^{B, i}\right)^{2} \frac{\sigma^{2}}{2}\right]$,

which yields an agent's optimal effort level of

$$
e^{i *}=\frac{\beta^{i}\left(1-t^{L, i}\right)\left(1-t^{B, i}\right)}{c} .
$$

Hence, managers will supply effort up to the point where $C^{\prime}\left(e^{i}\right)=\beta^{i}\left(1-t^{L, i}\right)\left(1-t^{B, i}\right)$. Optimal effort increases with the output dependent compensation component $\beta^{i}$ and decreases with the marginal cost of effort $c$ as well as with the labour tax rate $t^{L, i}$ and with the bonus tax $t^{B, i}$, i.e. $e^{i \prime}\left(t^{L, i}\right)<0$ and $e^{i \prime}\left(t^{B, i}\right)<0 .{ }^{6}$ Thus, higher taxes reduce effort.

Knowing $e^{i}$, the firm solves

$$
\underset{\alpha^{i}, \beta^{i}}{\operatorname{ax}} \pi=\Sigma_{i} \frac{\beta^{i}\left(1-t^{L, i}\right)\left(1-t^{B, i}\right)}{c}-\Sigma_{i}\left[\alpha^{i}+\frac{\left(\beta^{i}\right)^{2}\left(1-t^{L, i}\right)\left(1-t^{B, i}\right)}{c}\right]
$$

subject to each of the two managers' participation constraint

$$
\begin{array}{r}
{\left[\alpha^{i}+\frac{\left(\beta^{i}\right)^{2}\left(1-t^{L, i}\right)\left(1-t^{B, i}\right)^{2}}{c}\right]\left(1-t^{L, i}\right)-\frac{c}{2} \frac{\left(\beta^{i}\right)^{2}\left(1-t^{L, i}\right)^{2}\left(1-t^{B, i}\right)^{2}}{c^{2}}} \\
-r\left(\beta^{i}\right)^{2}\left(1-t^{L, i}\right)^{2}\left(1-t^{B, i}\right)^{2} \frac{\sigma^{2}}{2}=\overline{w^{i}} .
\end{array}
$$

This gives us the following optimal output dependent compensation component $\beta^{i *}$ and output-independent compensation component $\alpha^{i *}$

$$
\beta^{i *}=\frac{1}{1+t^{B, i}+r c \sigma^{2}\left(1-t^{B, i}\right)}
$$

and

$$
\alpha^{i *}=\frac{\overline{w^{i}}}{1-t^{L, i}}+\frac{\left(\beta^{i}\right)^{2}\left(1-t^{L, i}\right)\left(1-t^{B, i}\right)^{2}}{2 c}\left(r \sigma^{2} c-1\right),
$$

${ }^{6}$ See the Appendix A2 for the derivation. 
Accordingly, in country $A$ where the bonus tax is introduced, the optimal effort based compensation component $\beta^{A *}$ depends positively on the tax rate $t^{B, A}$, so $\frac{d \beta^{A}}{d t^{B, A}}>0 .{ }^{7}$ If in addition, $r \sigma^{2} c>1$, and as assumed before, no bonus tax is levied in country $\mathrm{B}$, so $t^{B, B}=0$, the piece-rate compensation component will be larger in the country levying the $\operatorname{tax}$, so $\beta^{A *}>\beta^{B *}$. Because of the introduction of the tax, the risk premium awarded to the agent can be reduced since the government now shares part of the risk, such that the optimal compensation contract is now tilted towards more effort based pay. In order to discuss the effects of the bonus tax on the compensation components and thus profits and implicitly dividends and welfare in the two economies, we distinguish between the following four different cases. We abstract for the moment from the existence of labour income taxes since the purpose of this paper is to focus on the effects of a bonus tax, and set for the moment $t^{L, A}=t^{L, B}=0$.

\subsubsection{Equal reservation wage and equal total net compensation}

In the first benchmark scenario mangers in both countries face the same reservation wage such that $\bar{w}^{A}=\bar{w}^{B}=\bar{w}$. Moreover, in line with the fair wage-effort hypothesis motivated by equity theory introduced in the famous contribution by Akerlof and Yellen (1990), who show that workers reduce their effort if their actual wages are lower than their fair wages, we require total net compensation to be equalized between countries. This so-called fairness constraint is consistent with findings of an extensive literature in personnel economics showing that incentives and different compensation policies indeed matter for an individual's effort. Indeed, following the introduction of the bonus tax, Deutsche Bank even considers changing the compensation in countries not affected by the bonus tax such that the net compensation is equal between countries.

$$
\left(1-t^{L, A}\right)\left[\alpha^{A *}+\left(1-t^{B, A}\right) \beta^{A *} e^{A *}\right]=\left(1-t^{L, B}\right)\left[\alpha^{B *}+\beta^{B *} e^{B *}\right]
$$

Thus, if the firm decides to award its two agents compensation packages such that their net of tax wages are equal, we can derive the following optimal compensation

\footnotetext{
${ }^{7}$ See the Appendix A1 for the derivation.
} 
components in country $A$ and $B$, respectively:

$$
\begin{gathered}
\beta^{A *}=\frac{1}{1+t^{B, A}+r c \sigma^{2}\left(1-t^{B, A}\right)} \\
\beta^{B *}=\frac{1}{1+r c \sigma^{2}} \\
\alpha^{A *}=\bar{w}+\frac{\left(\beta^{A}\right)^{2}\left(1-t^{B, A}\right)^{2}}{2 c}\left(r \sigma^{2} c-1\right), \\
\alpha^{B *}=\bar{w}+\frac{\left(\beta^{B}\right)^{2}}{2 c}\left(r \sigma^{2} c-1\right),
\end{gathered}
$$

Proposition 1. In case of equal reservation wages and equal total net compensation, the net of tax effort based compensation component in country $A$ equals the effort based compensation component in the no bonus tax country, B. Moreover, the effort independent wage components are also equalized.

$$
\beta^{A *}\left(1-t^{B, A}\right)=\beta^{B *} \quad \alpha^{A *}=\alpha^{B *}
$$

Proof. The result follows directly from comparing equations (15), (16), (17) and (18) as well as using equation (14) which requires total net compensation to be equalized between the two economies.

Since both managers have the same utility functions, the same degree of risk aversion as well as the same cost of effort functions, the 'insurance' part of the compensation package, namely the effort independent wage is the same, and given total net compensation has to be equal, the effort dependent wage component in the country levying the tax has to be larger.

From an ex ante perspective it is not possible to react to the tax by lowering the effort based compensation at other affiliates, as announced by Deutsche Bank, since this would violate the managers' participation constraint. Such a reaction is only viable ex post. Thus, the share of effort based compensation in the optimal contract is now higher because following the introduction of the bonus tax the government shares part of the risk. 


\subsubsection{Equal reservation wage and different total net compensation}

In the second scenario we drop the additional constraint that required total net compensation to be equalized. In this case, and still assuming equal reservation wages, we can derive the following relationship between the compensation components in the two countries.

Proposition 2. In case of equal reservation wages but with different total net compensation, the effort based compensation component in country $A$ is larger than the effort based compensation component in the no tax country, B. However, the effort independent wage component in the former is lower than the effort independent wage component in the latter.

$$
\beta^{A *}>\beta^{B *} \quad \alpha^{A *}<\alpha^{B *}
$$

Proof. The result follows directly from comparing equations (15), (16), (17) and (18)

Due to the introduction of the bonus tax, the piece rate component in country $A$ has to rise to induce the manager to employ more effort. However, since we assume reservation wages to be equal, the effort independent wage component has to be lower than in the no tax country and thus, once again the post tax optimal contract is tilted towards more effort based compensation.

\subsubsection{Different reservation wages and equal total net compensation}

In the following we relax the assumption of equal reservation wages. Using equations (12) and (13) and imposing the fairness constraint (14), we can derive the following relationship between the effort based compensation components in the two economies.

$$
\beta^{A *}\left(1-t^{B, A}\right)=\sqrt{\frac{2 c\left(\bar{w}^{A}-\bar{w}^{B}\right)}{c r \sigma^{2}+1}+\left(\beta^{B *}\right)^{2}}
$$


In addition, if the reservation wage in country $A$ is lower(higher) than in country $B$, so is the effort independent wage component.

$$
\overline{w^{A}} \gtrless \overline{w^{B}} \Rightarrow \alpha^{A *} \gtrless \alpha^{B *}
$$

\subsubsection{Different reservation wages and different total net compensation}

Finally, we consider the last and most complicated case in which neither reservation wages, nor total net compensation are equalized between countries. In this case, as in section 3.1.2, it follows from comparing equations (15) and (16) that $\beta^{A *}>\beta^{B *}$ if as assumed above, $r \sigma^{2} c>1$. Additionally, if the reservation wage in the country introducing the tax is higher (lower), so if $\bar{w}^{A} \gtrless \bar{w}^{B}$ it follows from comparing equations (17) and (18)that $\alpha^{A *} \gtrless \alpha^{B *}$.

\subsection{Relocation Possibilities Exist}

In this section we relax the assumption that managers cannot be relocated between countries and assume that the firm employs a number $N^{i}\left(t^{B, i}\right)$ of identical managers at each location and that the total numbers of managers is fixed

$$
N=N^{A}+N^{B}
$$

To convey our argument, we assume that the number of managers employed at each location just depends on the bonus tax. Given that this tax negatively influences effort, an introduction of a bonus tax in country $A$ will decrease the demand for managers at this location and increase the demand for managers in country $B$ by the same amount given the full employment condition (24). Accordingly

$$
\frac{d N^{A}}{d t^{B, A}}<0 \quad \text { and } \quad \frac{d N^{B}}{d t^{B, A}}=-\frac{d N^{A}}{d t^{B, A}}>0
$$

In this new extended framework, equations (3) and (4) now become 


$$
\begin{gathered}
Q^{i}=N^{i}\left(e^{i}+v\right) . \\
\underset{\alpha^{i}, \beta^{i}, N^{i}}{\operatorname{Max}} \pi=\Sigma_{i} E\left(Q^{i}\right)-\Sigma_{i} N^{i}\left(\alpha^{i}+\beta^{i} e^{i}\right),
\end{gathered}
$$

In this case, firms have a third control variable besides the two compensation components $\alpha^{i}$ and $\beta^{i}$, namely the number of managers employed at each location, $N^{i}$. We can thus derive from the firm's maximization problem the optimal number of managers at each location $N^{i *}$ which is implicitly determined by the wage and effort level at each location. ${ }^{8}$ Thus, $N^{i *}=\phi\left(\alpha^{i *}+\beta^{i *} e^{i *}, e^{i *}\right)$. Since effort in country $A$ negatively depends on the bonus tax, so does the number of managers employed at this location. In country $B$, no bonus tax is levied, effort is accordingly higher and given the fixed number of managers $N$, the firm relocates managers from country $A$ to country $B$. In this parsimonous model, as the demand for managers is just a function of the bonus tax and given that we consider identical individuals, the optimal effort level and the optimal compensation components do not change, so equations (13), (12) and (9) do not change.

\section{The Effect of the Bonus Tax on Profits, Divi- dends and Welfare}

To focus on the effect of the bonus tax on firm profits and accordingly dividends and welfare, we use the results derived in subsection 3.1.2 where reservation wages are equalized but no fairness constraint applies, as a benchmark. Once again we distinguish between two distinct cases, namely the first where managers cannot be relocated between countries and a second case where relocation is possible.

\footnotetext{
${ }^{8}$ See Appendix A.3 for the derivation of the first order condition.
} 


\subsection{No Relocation Possibilities}

As can be seen from equation (9), the bonus tax has a negative effect on effort in the country levying the tax. ${ }^{9}$ Therefore, the effort based compensation component has to rise, whereas given the same reservation wage in the two countries, the effort independent wage component declines following the introduction of the bonus tax. Accordingly, to be able to derive the overall effects on profits, one has to consider the combined overall effect. ${ }^{10}$ Plugging equations (15), (16), (17) and (18) into equation (10) and differentiating with respect to the bonus tax $t^{B, A}$, we can show that firm profits are negatively affected by the bonus tax. ${ }^{11}$

$$
\frac{d \pi}{d t^{B, A}}<0
$$

Proof. See the Appendix A.4.1.

Since the introduction of the tax lowers the managers' effort, output reacts negatively to the bonus tax and therefore, to induce the manager to provide more effort, the effort based compensation component has to rise, thus increasing the firm's wage costs and accordingly reducing profits.

Assume now that all profits are distributed to shareholders in the form of dividends, such that $\pi=D$. Therefore, since profits are negatively affected by the tax, so will be dividends. Furthermore, let us assume a fraction $\gamma$ of distributed profits are held by shareholders residing in country $A$ whereas $1-\gamma$ are distributed to shareholders residing in country $B$, so

$$
D^{A}=\gamma D \quad D^{B}=(1-\gamma) D
$$

\footnotetext{
${ }^{9}$ See the Appendix A2 for the derivation.

${ }^{10}$ Remember, as we do not require total net compensation to be equalized between countries, the compensation components in country B and thus output and accordingly profit in this country is not directly affected by the bonus tax.

${ }^{11}$ See the Appendix A.4.1 for the derivation.
} 
Given these additional assumptions, we can now analyze the effects of the bonus tax on welfare in the two countries respectively. Welfare is defined as the sum of the utility of the manager $U^{i}$, the dividends accruing to the shareholders in the respective economy $D^{i}$ and, for country $A$, the tax revenue raised following the introduction of the bonus tax $\lambda t^{B, i} \beta^{i} E\left(Q^{i}\right)$ where $\lambda>1$ is the shadow price of tax revenue.

$$
W^{i}=U^{i}+D^{i}+\lambda t^{B, i} \beta^{i} E\left(Q^{i}\right)
$$

Plugging into equation (29), equations (28), (3) and (2) and deriving equation (29) with respect to the bonus tax rate $t^{B, A}$, we can show that for the country introducing the tax, country $A$, the effect depends on the reaction of tax revenue to an increase in the tax rate. For large values of the bonus tax, so accordingly if $t^{B, A}>\frac{1+c r \sigma^{2}}{3+c r \sigma^{2}}$ tax revenue reacts negatively to an increase in the tax, and given the negative reaction of profits and thus dividends shown above, the overall welfare effect is negative. ${ }^{1213}$ For low values of the bonus tax, so if $t^{B, A}<\frac{1+c r \sigma^{2}}{3+c r \sigma^{2}}$ the overall effect on welfare in country $A$ depends on which of the two effects, namely the positive tax revenue effect or the negative dividend income effect outweighs. For small values of $\gamma$, so if most dividends are distributed to shareholders in the foreign economy, the negative dividend effect will be small so we can safely assume a positive effect on welfare in the country imposing the bonus tax. The opposite is true for large values of $\gamma$ and in case the negative effect on distributed income is higher than the positive tax revenue effect.

An unambiguous result can be, nevertheless, derived for welfare in the country which does not impose the tax. In this case, there is no bonus tax revenue so the only effect prevailing is the negative dividend income effect. Thus, welfare in country $B$ reacts negatively following the introduction of the bonus tax in country $A$. The

\footnotetext{
${ }^{12}$ See the Appendix A.5.1 for the proof.

${ }^{13}$ Given that the manager will only participate if he is given a reservation wage which is equal across countries, his utility does not change as a result of the bonus tax. His total compensation declines, however the effort cost is also lower due to lower effort and these two effects will cancel out
} 
effect is larger, the larger is the share of dividends held by residents of country $B$. To sum up

$$
\begin{gathered}
\frac{d W^{A}}{d t^{B, A}}<0 \quad \text { if } \quad t^{B, A}>\frac{1+c r \sigma^{2}}{3+c r \sigma^{2}} \text { or } \frac{d\left(t^{B, i} \beta^{i} E\left(Q^{i}\right)\right)}{d t^{B, i}}<\frac{d D^{A}}{d t^{B, i}} \\
\frac{d W^{A}}{d t^{B, A}}>0 \text { if } t^{B, A}<\frac{1+c r \sigma^{2}}{3+c r \sigma^{2}} \text { and } \frac{d\left(t^{B, i} \beta^{i} E\left(Q^{i}\right)\right)}{d t^{B, i}}>\frac{d D^{A}}{d t^{B, i}} . \\
\frac{d W^{B}}{d t^{B, A}}<0
\end{gathered}
$$

\subsection{Relocation Possibilities Exist}

We now turn once again to the scenario where managers can be relocated between countries. Plugging equations (15), (16), (17), (18) and (24) into equation (26) and differentiating with respect to the bonus tax $t^{B, A}$, one can see that firm profits are negatively affected by the bonus tax. ${ }^{14}$

$$
\frac{d \pi}{d t^{B, A}}<0
$$

Given the fixed number of managers and the fact that the decrease in the demand for managers in country $A$ exactly corresponds to the increase in the demand for managers in country $B$, the two basic affects which affect firm profits are the change in effort and the change in compensation in country $A$ following the introduction of the bonus tax. As in the case with no relocation possibilities, the agent's provision of effort decreases after the bonus tax is introduced such that the firm has to compensate her by increased effort based pay. Therefore, the negative reaction of effort and accordingly output to the bonus tax, combined with the increased wage costs, negatively affect firm profits. Furthermore, we now drop the assumption

\footnotetext{
${ }^{14}$ See the Appendix A.4.2 for the derivation.
} 
that no labour taxes apply, $t^{L, A}=t^{L, B}=0$ and just assume that labour income taxes are positive but equalized between countries, $t^{L, A}=t^{L, B}>0$. Accordingly, the new welfare function includes tax revenue generated by the labour income tax, $t^{L, i} N^{i}\left(\alpha^{i}+\left(1-t^{B, i}\right) \beta^{i} Q^{i}\right)$.

$$
W^{i}=U^{i}+D^{i}+\lambda\left[N^{i} t^{B, i} \beta^{i} E\left(Q^{i}\right)+t^{L, i} N^{i}\left(\alpha^{i}+\left(1-t^{B, i}\right) \beta^{i} e^{i}\right)\right]
$$

On the one hand, the country introducing the tax now loses in welfare terms compared to the case where no relocation is possible basically because it loses labour income tax revenue and potential bonus tax revenue. For values of $t^{B, A}$ above a certain threshold, the bonus tax revenue effect is negative and given the negative dividend income effect and the negative reaction of manager demand to the introduction of the bonus tax, welfare in country $A$ declines. Even if the direct bonus tax revenue effect $N^{A} \frac{d\left(t^{B, i} \beta^{i} E\left(Q^{i}\right)\right)}{d t^{B, i}}$ is positive, if it is small compared to the other negative effects induced by the introduction of the bonus tax, country $A$ still loses in welfare terms.

$$
\begin{gathered}
\frac{d W^{A}}{d t^{B, A}}<0 \text { if } \\
t^{B, A}>\frac{1+c r \sigma^{2}}{3+c r \sigma^{2}} \text { or } t^{B, A}<\frac{1+c r \sigma^{2}}{3+c r \sigma^{2}} \text { but } \\
N^{A} \frac{d\left(t^{B, i} \beta^{i} E\left(Q^{i}\right)\right)}{d t^{B, i}}<\frac{d D^{A}}{d t^{B, i}}+N^{A} \frac{d\left(t^{L, A}\left(\alpha^{A}+\left(1-t^{B, A}\right) \beta^{A} e^{A}\right)\right.}{d t^{B, A}} \\
+\frac{d N^{A}}{d t^{B, A}}\left(t^{B, A} \beta^{A} e^{A}+t^{L, A}\left(\alpha^{A}+\left(1-t^{B, A}\right) \beta^{A} e^{A}\right)\right) \\
\frac{d W^{A}}{d t^{B, A}}>0 \text { otherwise. }
\end{gathered}
$$

On the other hand, the country where no bonus tax is levied, may even display a positive welfare effect. Following the introduction of the tax in country $A$, the firm relocates managers such that country $B$ benefits from a higher labour income tax revenue $\frac{d N^{B}}{d t^{B, i}} t^{L, B}\left(\alpha^{B}+\beta^{B} e^{B}\right)$. If this positive effect is large enough to outweigh the negative dividend income effect $\frac{d D^{B}}{d t^{B, i}}$, welfare in country $B$ increases. 


$$
\begin{array}{lll}
\frac{d W^{B}}{d t^{B, A}}>0 \quad \text { if } & \frac{d N^{B}}{d t^{B, i}} t^{L, B}\left(\alpha^{B}+\beta^{B} e^{B}\right)>\frac{d D^{B}}{d t^{B, i}} \\
\frac{d W^{B}}{d t^{B, A}}<0 & \text { otherwise }
\end{array}
$$

\section{Conclusions and Suggestions for Future Research}

Given the recent discussions about the introduction of a bonus tax it is important to look into the possible effects of such a controversial policy proposal. Therefore, the purpose of this paper is to analyse the effects of introducing a bonus tax on compensation components and welfare, as well as to assess the incidence of the bonus tax. We consider two main scenarios. A first scenario where there are no relocation possibilities whereas in the second scenario the firm may relocate managers between countries.

In the first scenario we model a firm employing a manager in each of two countries, and use the framework of the Principal Agent model to shed light on the effects of a bonus tax introduced by one country. We consider four special cases: two where reservation wages are equal but total net compensation might be equal or differ between countries and two cases where reservation wages differ whereas total net compensation may be equal or different between countries. We solve for the optimal contracts in each country and show that the effort linked compensation component in the country introducing the tax will be higher. Accordingly, due to the introduction of the bonus tax, the government shares part of the risk, such that the optimal contract is tilted towards more effort based pay. Moreover, the bonus tax negatively affects effort and thus profits and dividends. Thus, the incidence of the tax is borne by the firm's shareholders. Regarding the welfare implications of such a tax, the country that does not introduce a bonus tax is worse off in terms of welfare as the dividend income accruing to its residents declines. The welfare implications for the country imposing the tax depend on the reaction of tax revenue to an increase in the bonus tax as well as on the relationship between the positive tax revenue effect and the negative dividend income effect. 
In the second scenario, the firm has an additional control variable, namely the number of managers employed in each country. As a response to the introduction of the bonus tax in one country, the firm relocates managers to the no tax country. In this case, welfare in the country introducing the tax is lower than in the first scenario whereas the country that does not levy a bonus tax might even gain in welfare terms.

Naturally, such a policy raises also additional questions which need to be addressed and are interesting for future research. Accordingly, one may consider if the tax involves any avoidance issues if bonuses are disguised as non-bonus components or the effects of such a tax if bonuses are paid in the form of stock options and thus linked to future performance.

\section{Appendix A}

\section{A.1 - Change in effort based compensation in country A with respect to a change in the bonus tax}

$$
\frac{d \beta^{A}}{d t^{B, A}}=\frac{r c \sigma^{2}-1}{1+t^{B, A}+r c \sigma^{2}\left(1-t^{B, A}\right)} \beta^{A}>0 \text { if } r c \sigma^{2}>1 .
$$

\section{A.2 - Change in effort in country $A$ with respect to a change in the bonus tax}

$$
\begin{array}{r}
\frac{d e^{A}}{d t^{B, A}}=\frac{\frac{d \beta^{i}}{d t^{B, A}}\left(1-t^{B, A}\right)}{c}-\frac{\beta^{i}}{c} \\
=\frac{\left(r c \sigma^{2}-1\right)\left(1-t^{B, A}\right)}{1+t^{B, A}+r c \sigma^{2}\left(1-t^{B, A}\right)}-1<0 .
\end{array}
$$

\section{A.3 - Profit maximization with relocation possibilities}

$$
\underset{\alpha^{i}, \beta^{i}, N^{i}}{\operatorname{Max}} \pi=\Sigma_{i} E\left(Q^{i}\right)-\Sigma_{i} N^{i}\left(\alpha^{i}+\beta^{i} e^{i}\right)
$$


s.t. the manager's participation constraint (5) and the full employment constraint $N=N^{A}+N^{B}$. If we denote by $\mu$ the Kuhn-Tucker multiplier for the full employment constraint, we can derive the optimal demand for managers in country $i$ as a function of effort and compensation in the respective country. The firm demands managers in each country up to the point where the marginal increase in expected output induced by a manager $e^{i}$ just equals the manager's marginal compensation $\alpha^{i}+\beta^{i} e^{i}$.

$$
\begin{gathered}
\frac{d L}{d N^{i}}=e^{i}-\alpha^{i}-\beta^{i} e^{i}-\mu=0, \\
\frac{d L}{d \mu}=N-N^{A}-N^{B}=0,
\end{gathered}
$$

Equation (40) implicitly determines the optimal demand for managers in country $i$ as $N^{i *}=\phi\left(\alpha^{i *}+\beta^{i *} e^{i *}, e^{i *}\right)$.

\section{A.4 - Change in profits with respect to a change in the bonus $\operatorname{tax}$}

\section{A.4.1 - No Relocation}

$$
\begin{array}{cc}
\frac{d \pi}{d t^{B, A}=} & \frac{\frac{d \beta^{i}}{d t^{B, A}\left(1-t^{B, A}\right)}}{c}-\frac{\beta^{i}}{c} \\
-\left[\frac{\beta^{i} \frac{d \beta^{i}}{d t^{B, A}}\left(1-t^{B, A}\right)^{2}\left(c r \sigma^{2}-1\right)}{c}-\frac{\left(\beta^{i}\right)^{2}\left(1-t^{B, A}\right)\left(c r \sigma^{2}-1\right)}{c}\right] & -\left[\frac{2 \beta^{i}\left(1-t^{B, A}\right) \frac{d \beta^{i}}{d t^{B, A}}}{c}-\frac{\left(\beta^{i}\right)^{2}}{c}\right]<0,
\end{array}
$$

Since

$$
\frac{\frac{d \beta^{i}}{d t^{B, A}}\left(1-t^{B, A}\right)}{c}-\frac{\beta^{i}}{c}<0 .
$$

from (38) and 


$$
\begin{aligned}
& \frac{\beta^{A} \frac{d \beta^{A}}{d t^{B, A}}\left(1-t^{B, A}\right)^{2}\left(c r \sigma^{2}-1\right)}{c}-\frac{\left(\beta^{A}\right)^{2}\left(1-t^{B, A}\right)\left(c r \sigma^{2}-1\right)}{c}+\frac{2 \beta^{A}\left(1-t^{B, A}\right) \frac{d \beta^{A}}{d t^{B, A}}-\frac{\left(\beta^{A}\right)^{2}}{c}}{c} \\
&= \frac{1}{c}\left[\frac{d \beta^{A}}{d t^{B, A}}\left(1-t^{B, A}\right)\left[\left(1-t^{B, A}\right)\left(c r \sigma^{2}-1\right)+2\right]-\beta^{A}\left[1+\left(1-t^{B, A}\right)\left(c r \sigma^{2}-1\right)\right]\right] \\
&= \frac{1}{c}\left[\frac{\left(r c \sigma^{2}-1\right)\left(1-t^{B, A}\right)}{1+t^{B, A}+r c \sigma^{2}\left(1-t^{B, A}\right)}\left[\left(1-t^{B, A}\right)\left(c r \sigma^{2}-1\right)+2\right]-1-\left(1-t^{B, A}\right)\left(c r \sigma^{2}-1\right)\right] \\
&= \frac{1}{c}\left[\frac{1}{1+t^{B, A}+r c \sigma^{2}\left(1-t^{B, A}\right)}\left[\left(r c \sigma^{2}-1\right)^{2}\left(1-t^{B, A}\right)^{2}-\left(1+t^{B, A}+r c \sigma^{2}\left(1-t^{B, A}\right)\right)\right]\right] \\
&+\frac{1}{c}\left[\frac{1}{1+t^{B, A}+r c \sigma^{2}\left(1-t^{B, A}\right)}\left[2\left(r c \sigma^{2}-1\right)\left(1-t^{B, A}\right)\right]\right] \\
&-\frac{1}{c}\left[\left(1-t^{B, A}\right)\left(r c \sigma^{2}-1\right)\left(1+t^{B, A}+r c \sigma^{2}\left(1-t^{B, A}\right)\right)\right] \\
&=\frac{1}{c}\left[\frac{1}{1+t^{B, A}+r c \sigma^{2}\left(1-t^{B, A}\right)}\left[t^{B, A}\left(3 r c \sigma^{2}-1\right)+3\right]\right]>0
\end{aligned}
$$

since $r c \sigma^{2}>1$ by assumption.

\section{A.4.2 - With Relocation}

$$
\begin{array}{r}
\frac{d \pi}{d t^{B, A}}=\frac{d N^{A}}{d t^{B, A}} e^{A}+N^{A} \frac{d e^{A}}{d t^{B, A}}+\frac{d N^{B}}{d t^{B, A}} e^{B} \\
-\frac{d N^{A}}{d t^{B, A}}\left(\alpha^{A}+\beta^{A} e^{A}\right)-N^{A}\left[\frac{d\left(\alpha^{A}+\beta^{A} e^{A}\right)}{d t^{B, A}}\right] \\
-\frac{d N^{B}}{d t^{B, A}}\left(\alpha^{B}+\beta^{B} e^{B}\right)<0,
\end{array}
$$

Using equations (40) and (41), the above equation simplifies to

$$
N^{A} \frac{d e^{A}}{d t^{B, A}}-N^{A}\left[\frac{d\left(\alpha^{A}+\beta^{A} e^{A}\right)}{d t^{B, A}}\right]<0 .
$$

which is negative. See the above derivation in A.4.1 


\section{A.5 - Change in welfare in country A with respect to a change in the bonus tax}

\section{A.5.1 - No Relocation}

$$
\begin{aligned}
& \frac{d W^{A}}{d t^{B, A}}=\frac{d U^{A}}{d t^{B, A}}+\frac{d t^{B, A} \beta^{A} E\left(Q^{A}\right)}{d t^{B, A}}+\frac{d D^{A}}{d t^{B, A}} \\
& \frac{d U^{A}}{d t^{B, A}}=e^{-r\left(w^{A}-C\left(e^{A}\right)\right)}\left[r\left(\frac{d w^{A}}{d t^{B, A}}-\frac{d C\left(e^{A}\right)}{d t^{B, A}}\right)\right] \\
& =e^{-r\left(w^{A}-C\left(e^{A}\right)\right)} * 0=0 \\
& \frac{d\left(t^{B, A} \beta^{A} E\left(Q^{A}\right)\right)}{d t^{B, A}}=\frac{d\left(\frac{t^{B, A}\left(\beta^{A}\right)^{2}\left(1-t^{B, A}\right)}{c}\right)}{d t^{B, A}} \\
& =\frac{\left(\beta^{A}\right)^{2}}{c}+\frac{2 \beta^{A} t^{B, A} \frac{d \beta^{A}}{d t^{B, A}}}{c}-\frac{2 t^{B, A}\left(\beta^{A}\right)^{2}}{c}-\frac{2 \beta^{A}\left(t^{B, A}\right)^{2} \frac{d \beta^{A}}{d t^{B, A}}}{c} \\
& =1+2 t^{B, A} \frac{r c \sigma^{2}-1}{1+t^{B, A}+r c \sigma^{2}\left(1-t^{B, A}\right)}-2 t^{B, A}\left(1+t^{B, A} \frac{r c \sigma^{2}-1}{1+t^{B, A}+r c \sigma^{2}\left(1-t^{B, A}\right)}\right) \\
& =\frac{1}{1+t^{B, A}+r c \sigma^{2}\left(1-t^{B, A}\right)}\left[1+r c \sigma^{2}-t^{B, A}\left(3+r c \sigma^{2}\right)\right]>0 \text { if } t^{B, A}<\frac{1+r c \sigma^{2}}{3+r c \sigma^{2}}(47)
\end{aligned}
$$

\section{A.5.2 - With Relocation}

$$
\begin{aligned}
& \frac{d W^{A}}{d t^{B, A}}=\frac{d U^{A}}{d t^{B, A}}+N^{A} \lambda \frac{d\left(t^{B, A} \beta^{A} e^{A}\right)}{d t^{B, A}}+\lambda N^{A} \frac{d\left(t^{L, A}\left(\alpha^{A}+\left(1-t^{B, A}\right) \beta^{A} e^{A}\right)\right.}{d t^{B, A}} \\
&+\lambda \frac{d N^{A}}{d t^{B, A}}\left[t^{B, A} \beta^{A} e^{A}+t^{L, A}\left(\alpha^{A}+\left(1-t^{B, A}\right) \beta^{A} e^{A}\right)\right]+\frac{d D^{A}}{d t^{B, A}}
\end{aligned}
$$

If $t^{B, A}>\frac{1+r c \sigma^{2}}{3+r c \sigma^{2}}$, then as in subsection A.4.1 the bonus tax revenue effect is negative and since we know that the introduction of the bonus tax reduces the demand for managers $\frac{d N^{A}}{d t^{B, A}}<0$ and has a negative effect on profits and accordingly on distributed dividends, $\frac{d D^{A}}{d t^{B, A}}<0$, the overall welfare effect in country $A$ 
is negative. The same result applies even if we have a direct positive bonus tax revenue effect but the effect is small compared to the negative dividend income effect $\frac{d D^{A}}{d t^{B, A}}$, the negative labour income tax revenue effect $N^{A} \frac{d N^{A}}{d t^{B, A}} t^{L, A}\left(\alpha^{A}+(1-\right.$ $\left.\left.\left.t^{B, A}\right) \beta^{A} e^{A}\right)\right)+N^{A} \frac{d\left(t^{L, A}\left(\alpha^{A}+\left(1-t^{B, A}\right) \beta^{A} e^{A}\right)\right.}{d t^{B, A}}$ and the indirect negative bonus tax revenue effect $\frac{d N^{A}}{d t^{B, A}}\left(t^{B, A} \beta^{A} e^{A}\right)$ induced by the relocation of managers to country $B$.

Given that as a response to the introduction of the bonus tax firms may now relocate managers to the no bonus tax country, this country benefits and may even display positive welfare results if the positive labour income tax revenue effect $\frac{d N^{B}}{d t^{B, A}} t^{L, B}\left(\alpha^{B}+\beta^{B} e^{B}\right)$ is large enough to compensate for the negative dividend income effect $\frac{d D^{B}}{d t^{B, A}}$.

$$
\frac{d W^{B}}{d t^{B, A}}=\frac{d U^{B}}{d t^{B, A}}++\lambda \frac{d N^{B}}{d t^{B, A}} t^{L, B}\left(\alpha^{B}+\beta^{B} e^{B}\right)+\frac{d D^{B}}{d t^{B, A}}
$$

\section{References}

Akerlof, G.A. and J.L. Yellen, 2000, The Fair Wage-Effort Hypothesis and Unemployment, Quarterly Journal of Economics, Vol. CV, Issue 2, pp. 255-283.

Baumol, W.J., 1990, Entrpreneurship: Productive, Unproductive, and Destructive, Journal of Political Economy, Vol. 98, No. 5, pp. 893-920.

Bolton, P. and M. Dewatripont, 2005, Contract Theory, , MIT Press, Cambridge, Massachusetts.

Brunello, G., S. Comi and D. Sonedda, 2006, Income Taxes and the Composition of Pay, IZA Discussion Paper No. 2203.

Egger, P. and D. Radulescu, 2010, Labour Taxation and Foreign Direct Investment, Scandinavian Journal of Economics, forthcoming.

Financial Times, 2009, What Banker Wants to Be in the UK?, http://www.ft.com/cms/s/0/6284fdba-e4c3-11de-96a2-00144feab49a.html. 
Frankfurter Allgemeine Zeitung, 2009, Deutsche Bank will Last der Bonus-Steuer mindern - Britische Strafabgabe soll auf alle Mitarbeiter und Aktionäre umgelegt werden, FAZ, 19 December 2009 No. 295, p.11.

CEBR, 2009, Press release, 21 October 2009. http://www.cebr.com/Resources/CEBR/Press Releases/London and the City Prospects Press Release Oct 2009 City Bonuses.pdf.

Giertz, S. H., E. Saez and J. Slemrod, 2009, The Elasticity of Taxable Income With Respect to Marginal Tax Rates: A Critical Review, NBER Working Paper, No. 15012, NBER.

Gruber, J. and E. Saez, 2002, The Elasticity of Taxable Income: Evidence and Implications, Journal of Public Economics, Vol. 84, No. 1, pp. 1-32.

Gupta, B. and C. Viauroux, 2009, Is Tax Sharing Optimal? An Analysis in a Principal Agent Framework, UMBS Economic Department Working Paper No. 09-105.

Hall, B.J. and J.B. Liebman, 2000, The Taxation of Executive Compensation, Tax Policy and the Economy, Vol. 14, pp. 1-44.

Holmstrom, B. and P. Milgrom, 1987, Aggregation and Linearity in the Provision of Intertemporal Incentives, Econometrica, Vol. 55, pp. 303-328.

Katuscák, P., 2009, Taxes and Executive Compensation, CESifo Economic Studies, Vol. 55, No. 3/4, pp. 542-568.

Phillipon, T. and A. Reshef, 2008, Wages and Human Capital in the U.S. Financial Industry: 1909-2006, NBER Working Paper, No. 14644, NBER.

Toronto Summit, 2010 , Toronto Summit- Summit Themes, http://g20.gc.ca/toronto-summit/summit-themes/ 


\section{CESifo Working Paper Series}

for full list see www.cesifo-group.org/wp

(address: Poschingerstr. 5, 81679 Munich, Germany, office@cesifo.de)

2965 Jan C. van Ours and Lenny Stoeldraijer, Age, Wage and Productivity, February 2010

2966 Michael Hoel, Climate Change and Carbon Tax Expectations, February 2010

2967 Tommaso Nannicini and Roberto Ricciuti, Autocratic Transitions and Growth, February 2010

2968 Sebastian Brauer and Frank Westermann, A Note on the Time Series Measure of Conservatism, February 2010

2969 Wolfram F. Richter, Efficient Education Policy - A Second-Order Elasticity Rule, February 2010

2970 Tomer Blumkin, Yoram Margalioth and Efraim Sadka, Taxing Children: The Redistributive Role of Child Benefits - Revisited, February 2010

2971 Chang Woon Nam and Georg Wamser, Application of Regionally Varying Additionality Degrees in the Practice of EU Cohesion Policy, February 2010

2972 Ali Bayar, Frédéric Dramais, Cristina Mohora, Masudi Opese and Bram Smeets, Modeling Russia for Climate Change Issues, February 2010

2973 Magnus Söderberg, Informal Benchmarks as a Source of Regulatory Threat in Unregulated Utility Sectors, March 2010

2974 Piotr Wdowiński and Marta Malecka, Asymmetry in Volatility: A Comparison of Developed and Transition Stock Markets, March 2010

2975 Frans van Winden, Michal Krawczyk and Astrid Hopfensitz, Investment, Resolution of Risk, and the Role of Affect, March 2010

2976 Hyun-Ju Koh and Nadine Riedel, Do Governments Tax Agglomeration Rents?, March 2010

2977 Johann K. Brunner and Susanne Pech, Optimum Taxation of Bequests in a Model with Initial Wealth, March 2010

2978 Guglielmo Maria Caporale and Nicola Spagnolo, Stock Market Integration between three CEECs, Russia and the UK, March 2010

2979 Florian Englmaier, Ales Filipi and Ravi Singh, Incentives, Reputation and the Allocation of Authority, March 2010 
2980 Konstantinos Angelopoulos, George Economides and Apostolis Philippopoulos, What is the Best Environmental Policy? Taxes, Permits and Rules under Economic and Environmental Uncertainty, March 2010

2981 Frederick van der Ploeg, Rapacious Resource Depletion, Excessive Investment and Insecure Property Rights, March 2010

2982 Wolfram F. Richter and Christoph Braun, Efficient Subsidization of Human Capital Accumulation with Overlapping Generations and Endogenous Growth, March 2010

2983 Francesco Cinnirella, Marc Piopiunik and Joachim Winter, Why Does Height Matter for Educational Attainment? Evidence from German Pre-Teen Children, March 2010

2984 Bernard Van Praag, Well-being Inequality and Reference Groups - An Agenda for New Research, March 2010

2985 Francesca Barion, Raffaele Miniaci, Paolo M. Panteghini and Maria Laura Parisi, Profit Shifting by Debt Financing in Europe, March 2010

2986 Alexander Haupt and Magdalena Stadejek, The Choice of Environmental Policy Instruments: Energy Efficiency and Redistribution, March 2010

2987 John Komlos and Marek Brabec, The Trend of BMI Values among US Adults, March 2010

2988 Emanuele Massetti and Lea Nicita, The Optimal Climate Policy Portfolio when Knowledge Spills across Sectors, March 2010

2989 Helmut Rainer and Thomas Siedler, Family Location and Caregiving Patterns from an International Perspective, March 2010

2990 Toru Kikuchi and Ngo Van Long, A Simple Model of Service Offshoring with Time Zone Differences, March 2010

2991 Assaf Razin, Efraim Sadka and Benjarong Suwankiri, Migration and the Welfare State: Dynamic Political-Economy Theory, March 2010

2992 Bård Harstad, Buy Coal! Deposit Markets Prevent Carbon Leakage, March 2010

2993 Axel Dreher, Stephan Klasen, James Raymond Vreeland and Eric Werker, The Costs of Favoritism: Is Politically-driven Aid less Effective?, March 2010

2994 Sven Neelsen and Thomas Stratmann, Effects of Prenatal and Early Life Malnutrition: Evidence from the Greek Famine, March 2010

2995 Claude Hillinger and Bernd Süssmuth, The Quantity Theory of Money: An Assessment of its Real Linchpin Prediction, March 2010

2996 Matthew M. Chingos and Martin R. West, Do More Effective Teachers Earn More Outside of the Classroom?, March 2010 
2997 Laurence Jacquet and Dirk Van de gaer, A Comparison of Optimal Tax Policies when Compensation or Responsibility Matter, March 2010

2998 Valentina Bosetti, Carlo Carraro, Romain Duval and Massimo Tavoni, What Should we Expect from Innovation? A Model-Based Assessment of the Environmental and Mitigation Cost Implications of Climate-Related R\&D, March 2010

2999 Scott Alan Carson, Nineteenth Century Stature and Family Size: Binding Constraint or Productive Labor Force?, March 2010

3000 Jukka Pirttilä and Ilpo Suoniemi, Public Provision, Commodity Demand and Hours of Work: An Empirical Analysis, March 2010

3001 Bertrand Candelon and Franz C. Palm, Banking and Debt Crises in Europe: The Dangerous Liaisons?, March 2010

3002 Joan Costa-i-Font and Marin Gemmill-Toyama, Does Cost Sharing really Reduce Inappropriate Prescriptions?, March 2010

3003 Scott Barrett, Climate Treaties and Backstop Technologies, March 2010

3004 Hans Jarle Kind, Tore Nilssen and Lars Sørgard, Price Coordination in Two-Sided Markets: Competition in the TV Industry, March 2010

3005 Jay Pil Choi and Heiko Gerlach, Global Cartels, Leniency Programs and International Antitrust Cooperation, March 2010

3006 Aneta Hryckiewicz and Oskar Kowalewski, Why do Foreign Banks Withdraw from other Countries? A Panel Data Analysis, March 2010

3007 Eric A. Hanushek and Ludger Woessmann, Sample Selectivity and the Validity of International Student Achievement Tests in Economic Research, March 2010

3008 Dennis Novy, International Trade and Monopolistic Competition without CES: Estimating Translog Gravity, April 2010

3009 Yin-Wong Cheung, Guonan Ma and Robert N. McCauley, Renminbising China's Foreign Assets, April 2010

3010 Michel Beine and Sara Salomone, Migration and Networks: Does Education Matter more than Gender?, April 2010

3011 Friedrich Schneider, Tilman Brück and Daniel Meierrieks, The Economics of Terrorism and Counter-Terrorism: A Survey (Part I), April 2010

3012 Friedrich Schneider, Tilman Brück and Daniel Meierrieks, The Economics of Terrorism and Counter-Terrorism: A Survey (Part II), April 2010

3013 Frederick van der Ploeg and Steven Poelhekke, The Pungent Smell of "Red Herrings": Subsoil Assets, Rents, Volatility and the Resource Curse, April 2010 
3014 Vjollca Sadiraj, Jan Tuinstra and Frans van Winden, Identification of Voters with Interest Groups Improves the Electoral Chances of the Challenger, April 2010

3015 Guglielmo Maria Caporale, Davide Ciferri and Alessandro Girardi, Time-Varying Spot and Futures Oil Price Dynamics, April 2010

3016 Scott Alan Carson, Racial Differences in Body-Mass Indices for Men Imprisoned in $19^{\text {th }}$ Century US Prisons: A Multinomial Approach, April 2010

3017 Alessandro Fedele, Paolo M. Panteghini and Sergio Vergalli, Optimal Investment and Financial Strategies under Tax Rate Uncertainty, April 2010

3018 Laurence Jacquet, Take it or Leave it: Take-up, Optimal Transfer Programs, and Monitoring, April 2010

3019 Wilhelm Kohler and Jens Wrona, Offshoring Tasks, yet Creating Jobs?, April 2010

3020 Paul De Grauwe, Top-Down versus Bottom-Up Macroeconomics, April 2010

3021 Karl Ove Aarbu, Demand Patterns for Treatment Insurance in Norway, April 2010

3022 Toke S. Aidt and Jayasri Dutta, Fiscal Federalism and Electoral Accountability, April 2010

3023 Bahram Pesaran and M. Hashem Pesaran, Conditional Volatility and Correlations of Weekly Returns and the VaR Analysis of 2008 Stock Market Crash, April 2010

3024 Stefan Buehler and Dennis L. Gärtner, Making Sense of Non-Binding Retail-Price Recommendations, April 2010

3025 Leonid V. Azarnert, Immigration, Fertility, and Human Capital: A Model of Economic Decline of the West, April 2010

3026 Christian Bayer and Klaus Wälde, Matching and Saving in Continuous Time: Theory and 3026-A Matching and Saving in Continuous Time: Proofs, April 2010

3027 Coen N. Teulings and Nick Zubanov, Is Economic Recovery a Myth? Robust Estimation of Impulse Responses, April 2010

3028 Clara Graziano and Annalisa Luporini, Optimal Delegation when the Large Shareholder has Multiple Tasks, April 2010

3029 Erik Snowberg and Justin Wolfers, Explaining the Favorite-Longshot Bias: Is it RiskLove or Misperceptions?, April 2010

3030 Doina Radulescu, The Effects of a Bonus Tax on Manager Compensation and Welfare, April 2010 